\title{
Influence de l'extrusion de mélanges de graines de lin et d'orge, de graines de pois et de colza, et de fèves de soja, sur la dégradabilité dans le rumen de leurs fractions azotée et lipidique et sur leur composition en acides gras
}

\author{
A Clinquart, L Istasse, C Van Eenaeme, M Diez, \\ I Dufrasne, JM Bienfait
}

Service de Nutrition, Fac Méd Vét, université de Liège, bât B 43, Sart Tilman 4000 Liège, Belgique

Summary - Effects of extrusion of linseed mixed with barley, pea mixed with rapeseed and soya bean on degradability in the rumen of nitrogen and ether extract and on fatty acid composition. Three feedstuffs, either ground or extruded were compared. Extrusion reduced the degradability of dry matter and nitrogen. There was also an increase in the proportion of C14:0 and C16:0 and a reduction in unsaturated fatty acids except for soya bean. After an 8-h incubation, the changes in fatty acid composition were found to be small.

L'extrusion protège partiellement les protéines des graines oléoprotéagineuses de la dégradation microbienne et élimine leurs facteurs antinutritionnels (Melcion, 1988). Cependant elle est très difficile à appliquer aux graines dont la teneur en matière grasse approche ou dépasse $40 \%$. L'objectif de ce travail était de déterminer l'effet de l'extrusion sur la dégradabilité dans le rumen et la composition en acides gras de 3 graines oléagineuses : lin, colza et soja, dont 2 étaient associées à de l'orge ou à des pois.

Matériel et méthodes - Des mélanges de graines de lin $(50 \%)$ et d'orge $(50 \%)(G L O)$, de graines de pois $(80 \%)$ et de colza $(20 \%)(\mathrm{PC})$, et des fèves de soja (FS) ont été broyés ou extrudés (appareil monovis; températures maximales : 160,140 et $140^{\circ} \mathrm{C}$ respectivement) puis broyés. Les dégradations des matières azotées (DMA) ont été mesurées in situ (Mehrez et Orskov, 1977), 2 fois par aliment, dans le rumen de 3 bœufs. La dégradation de l'extrait éthéré (DEE) a été déterminée, 3 fois par aliment, après $8 \mathrm{~h}$ d'incubation. La composition en acides gras a été déterminée par chromatographie en phase gazeuse après extraction, selon la technique de Ter Meulen et al (1975). Les résultats ont été soumis au test $t$ de Student.
Résultats et discussion - L'extrusion n'a pas modifié la teneur en matière azotée des aliments $(18,3 \% ; 39,3 \%$ et $23,4 \%$ dans la MS respectivement pour les GLO, FS et $P C$ ). Pendant toute la durée de l'incubation, elle a réduit la DMA du mélange GLO $(P \leq 0,05$ à $8 h$ et $P \leq 0,001$ pour les autres heures) (fig 1). Au-delà de $8 \mathrm{~h}$, elle a aussi réduit la DMA de FS $(P \leq 0,01$ à partir de $24 \mathrm{~h})$ et $\mathrm{PC}(P \leq 0,001$ à partir de $24 \mathrm{~h})$. Par contre, au cours des premières heures, elle a entraîné une augmentation de la DMA ( $P \leq 0,05$ pour FS). L'extrusion a légèrement diminué (de $0,5 \mathrm{~g} \%$ en moyenne) la teneur en extrait éthéré des aliments qui, sous forme broyée, était de $20,0 \%$ (GLO), $18,8 \%$ (FS) et 10,2\% (PC) dans la MS. Elle a diminué la DEE du mélange GLO $(59,5$ vs $67,1 \% ; P \leq 0,01)$ et augmenté celle des FS (47,0 vs $18,1 \%$; $P \leq 0,001)$ et $\mathrm{PC}(73,5$ vs $44,5 \% ; P \leq$ $0,001)$. L'extrusion, appliquée aux aliments GLO et PC, a entraîné, à des degrés de signification divers, une augmentation des $\mathrm{C} 14: 0$ et $\mathrm{C} 16: 0$ au détriment des $\mathrm{C} 18$, associée à une hydrogénation des $\mathrm{C} 18$ (tableau I). Ces effets n'ont pas été observés lors du traitement des FS. L'hydrogénation 
des acides gras après $8 \mathrm{~h}$ d'incubation dans le rumen a été très faible pour les aliments broyés et n'a pas été modifiée par l'extrusion de l'aliment. L'extrusion a donc permis, d'une part, une solubilisation plus importante de certains composants rapidement fermentescibles des 3 aliments, excepté le GLO, et, d'autre part, une protection contre les attaques microbiennes, principalement de la fraction azotée non soluble. L'effet différent de l'extrusion sur la DEE8 de ces 3 aliments peut s'expliquer par la nature différente des aliments (Michalet-Doreau et al, 1987) et par les températures maximales différentes $\left(160^{\circ} \mathrm{C}\right.$ pour GLO vs $140^{\circ} \mathrm{C}$ pour FS et $P C$ ).
En conclusion, les effets de l'extrusion sur les DMA et DEE ont varié selon les aliments. L'extrusion n'a pas protégé les acides gras polyinsaturés.

Remerciements - Travail subventionné par I'IRSIA, rue de Crayer, 6, B-1050 Bruxelles.

Mehrez AZ, Orskov ER (1977) J Agric Sci Camb $88,645-650$

Melcion JP (1988) Symp Eur CPCIA CuissonExtrusion, Nantes, 25-27 octobre 1988

Michalet-Doreau B, Doreau M, Voisin A, Bogaert C (1987) Cuisson-extrusion, Les colloques de I'INRA, $n^{\circ} 41$, ed INRA, Paris, 249-258

Ter Meulen VU, Nordbeck H, Molnar S (1975) Zeit Tierphysiol Tieremähr Futterm 35, 144-163

Tableau I. Composition en acides gras (exprimée en \% molaire) des aliments et de leurs résidus après $8 \mathrm{~h}$ d'incubation.

\begin{tabular}{ccccccc}
\hline & \multicolumn{2}{c}{$\begin{array}{c}\text { Lin }+ \text { orge (GLO) } \\
\text { Broyé }\end{array}$} & $\begin{array}{c}\text { Fèves de soja (FS) } \\
\text { Extrudé }\end{array}$ & Broyé & Extrudé & \multicolumn{2}{c}{$\begin{array}{c}\text { Pois + colza }(P C) \\
\text { Broyé }\end{array}$} & Extrudé \\
\hline Aliment & & & & & & \\
C14:0 & 0,1 & $3,2^{*}$ & 1,4 & 0,8 & 0,7 & 5,2 \\
C16:0 & 6,3 & 10,3 & 11,8 & 11,3 & 9,8 & 10,8 \\
C18:0 & 4,9 & $3,9^{*}$ & 4,1 & $3,4^{*}$ & 4,4 & $2,3^{*}$ \\
C18:1 & 17,9 & $18,8^{*}$ & 21,6 & 21,0 & 53,5 & 50,5 \\
C18:2 & 16,9 & $21,1^{* *}$ & 53,4 & $55,1^{*}$ & 21,9 & $25,1^{*}$ \\
C18:3 & 53,8 & $42,6^{*}$ & 7,8 & 8,4 & 8,9 & $6,2^{*}$ \\
Résidu & & & & & & \\
C14:0 & 0,4 & 2,2 & 0,3 & 1,6 & 6,2 & 4,2 \\
C16:0 & 8,8 & 11,6 & 11,9 & 14,5 & 14,3 & 12,8 \\
C18:0 & 4,9 & 5,2 & 4,2 & 5,8 & 4,0 & 5,9 \\
C18:1 & 19,4 & 20,0 & 21,8 & 26,9 & 51,4 & 45,9 \\
C18:2 & 18,8 & 22,8 & 54,5 & 45,4 & 19,8 & 24,9 \\
C18:3 & 47,7 & 38,2 & 7,4 & 5,9 & 4,3 & 6,4 \\
\hline
\end{tabular}

Comparaison broyé/extrudé: * $P \leq 0,05 ;{ }^{* *} P \leq 0,01$.
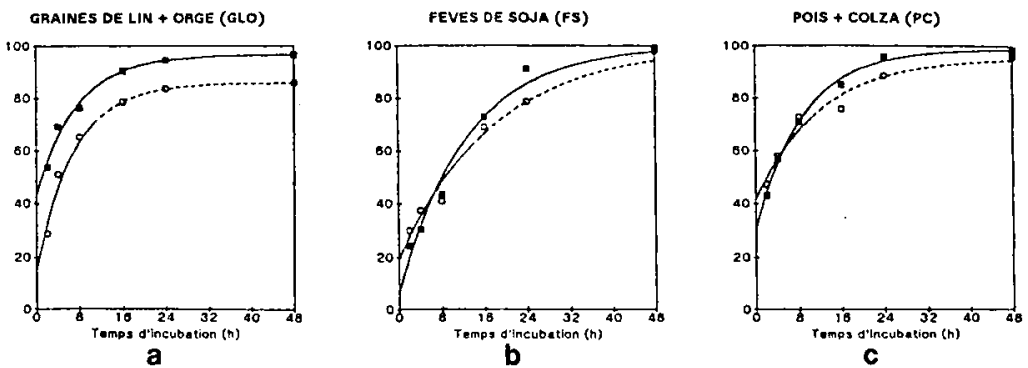

Fig 1. Évolution de la dégradation des matières azotées (en \%) des aliments sous formes broyée ( $\square$ ) et extrudée (0).

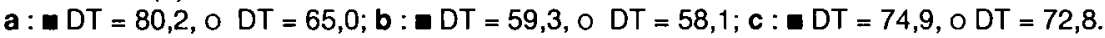

